\title{
1 Multistage Extraction and Purification of Waste Sargassum natans to Produce Sodium Alginate: An Optimization Approach
}

3 Akeem Mohammed ${ }^{\mathrm{a}}$, Rakesh Bissoon ${ }^{\mathrm{a}}$, Elisheba Bajnath ${ }^{\mathrm{a}}$, Kristy Mohammed ${ }^{\mathrm{a}}$, Thérèse Lee ${ }^{\mathrm{a}}$, 4 Meera Bissram ${ }^{\mathrm{a}}$, Nigel John ${ }^{\mathrm{b}}$, Nigel. K Jalsa ${ }^{\mathrm{b}}$, Koon-Yang Lee ${ }^{\mathrm{c}}$, Keeran Ward ${ }^{\mathrm{a}}$

6 a Department of Chemical Engineering, University of the West Indies, St. Augustine, Trinidad, 7 WI.

8 bepartment of Chemistry, University of the West Indies, St. Augustine, Trinidad, WI.

$9 \quad$ 'Department of Aeronautics, Imperial College London, SW7 2AZ, London, UK.

10 Telephone: + 1868730 1930, Email: Keeran.Ward@sta.uwi.edu

12 Abstract

13 Sargassum in the Caribbean region has affected the livelihood of several coastal communities due 14 to the influx of large quantities of the seaweed in recent times. This article seeks to explore how 15 waste Sargassum natans can be utilized to produce sodium alginate. The novelty in this research 16 lies in the optimization process, whereby multistage extraction and precipitation were investigated 17 over commonly used single stage processing, in an effort to maximize both yield and purity. The 18 results showed that a maximum yield of $19 \%$ was observed after 1 stage, while the purity was $74 \%$ 19 after 4 stages. In addition, optimization of the multistage precipitation process using the Global 20 Optimization Toolbox in MATLAB R2017b provided a novel model which indicated that a

21 compromise between the maximum purity and yield can be obtained at 3 stages; $71-74 \%$ and 12 $22-16 \%$ respectively. Furthermore, characterization was done using FTIR and NMR, with results 23 comparable to a commercial sodium alginate brand, giving absorption bands at $1610 \mathrm{~cm}^{-1}$ and $241395 \mathrm{~cm}^{-1}$ and an $\mathrm{M} / \mathrm{G}$ ratio of 0.51 respectively.

25 Keywords: Sodium Alginate; Sargassum natans; NMR; Multistage Extraction; Multistage 26 Precipitation; Optimization. 


\section{1. Introduction}

30 Alginates are polysaccharides that are naturally present in the cell walls of brown seaweeds and

31 are composed of linear binary copolymers of $(1 \rightarrow 4)$-linked $\beta$-D-mannuronic acid $(\mathrm{M})$ and $\propto$-L-

32 guluronic acid (G) monomers (Torres et al., 2007). Alginate exists as a mixed salt of cations that

33 are found in sea water; mainly magnesium, sodium and calcium ions (Larsen, Salem, Sallam,

34 Mishrikey, \& Beltagy, 2003), and naturally possesses carboxyl groups in each constituent $\mathrm{M}$ and

$35 \mathrm{G}$ block residue. The $\mathrm{M} / \mathrm{G}$ ratio varies depending on the algal species as well as the specific tissues

36 of a given species (Donati et al., 2003). The mannuronic acid forms $\beta(1 \rightarrow 4)$ linkage, which leads

37 to the $\mathrm{M}$ block segments possessing linear and flexible conformations. The guluronic acid has $\alpha$

38 (1 $\rightarrow 4)$ linkage that introduces steric hindrance around the carboxyl groups, causing the $\mathrm{G}$ block segments to possess folded and rigid structural conformations (Avella et al., 2007).

The most expedient and distinctive property of alginates is their ability to react with divalent metal ions, specifically calcium ions to produce water-insoluble calcium alginate via ionic crosslinking (Grant, Morris, Rees, Smith, \& Thom, 1973). The divalent calcium cation, $\mathrm{Ca}^{2+}$, fits into the guluronic acid structure like 'an egg in an egg-box', which leads to an increase in the water resistance of calcium alginate films. This increase in water resistance is due to the binding of the alginic acid by forming junction zones (Rhim, 2004). The backbone of the G segments form the water-insoluble calcium alginate due to strong interactions between the divalent cations and the COO- groups of the base residual of guluronic acid (Avella et al., 2007).

These sodium alginates are widely used as viscosifying/gelling agents and stabilizers in the biomedical, cosmetic, textile, pharmaceutical and food industry due to their rheological properties (Draget, Smidsrød, \& Skjåk-Bræk, 2005). In the pharmaceutical field, calcium alginate hydrogels are used as a matrix for drug encapsulation, sustained release of cells/delivery vehicle of drugs, pill disintegration, wound healing and tissue engineering (Lee \& Mooney, 2012). More recently, there has been growing attention into the uses of calcium alginate as structural supporting

54 biomaterials for tissue (teeth, bone and cartilage), reconstruction (Chen et al., 2017; Wahl et al.,

55 2015), as taste masking agents (Rajesh, Bhatt, Brahmbhatt, Anand, \& Popat, 2015), wound 56 dressings (Carella, Maruccia, Fino, \& Onesti, 2013), and as injectable vehicles for topical drug 57 delivery systems (Almeida, Amaral, Lobão, \& Lobo, 2014; Barzegari \& Saei, 2012). Also, calcium 
alginate microparticles are being developed to treat diabetes and Parkinson's disease (Calafiore \&

59 Basta, 2014; Hegarty, O’Keeffe, \& Sullivan, 2014). Furthermore, new research is underway into

60 the use of calcium alginate-based bio-inks in 3D bio-printing for direct fabrication of artificial

61 living tissue (Axpe \& Oyen, 2016).

62 The procedure to extract sodium alginate from different types of brown seaweeds uses specific

63 methods depending on the growth conditions of the seaweed. Commercial sodium alginate is

64 typically extracted from brown seaweed such as Laminaria hyperborea,Laminaria

65 digitata, Ascophyllum nodosum, Macrocystis pyrifera and to a lesser extent from Laminaria

66 japonica, Eclonia maxima and Sargassum sp. (Smidsrød \& Skja k-Brtk, 1990).

67 The Caribbean has seen a massive influx of Sargassum in 2011-2018, which creates a variety of

68 problems for coastal residents as it affects fisher livelihoods; difficulty in launching boats, restricts

69 access to fishery resources, affects tourism and decomposition results in a very foul smell. The

70 Sargassum found in Trinidad can be identified as Sargassum natans due to its morphological

71 characteristics such as its lanceolate blades with aculeate teeth, lateral smooth branches and air

72 bladders which correlates with previous investigations (Schneider \& Searles., 1991; Széchy,

73 Guedes, Baeta-Neves, \& Oliveira, 2012).

74 Extraction is usually done via acid pretreatment of the seaweed followed by treatment with 75 aqueous alkali solution. The extract is obtained and then precipitated to form alginic acid followed 76 by conversion and purification to form dry powered sodium alginate. However, in the conventional 77 extraction process, single stage batch extraction and precipitation is carried out. It is anticipated 78 that multistage extraction and precipitation can provide a better yield and a higher quality of 79 sodium alginate. Therefore, in this work we report the use of a multistage extraction and 80 precipitation process of a waste brown seaweed (Sargassum) to produce sodium alginate. We also 81 report a novel optimized model for the purification of the sodium alginate extracted. Both the 82 yield and purity of the sodium alginate extracted from Sargassum natans are discussed in this work 83 showing that through multistage extraction and precipitation, it is possible to extract high yield 84 and purity sodium alginate. 


\section{Materials and methods}

\section{$\underline{\text { 2.1. Materials }}$}

The Sargassum natans seaweed was collected from both Manzanilla and Mayaro Bays on the

91 Eastern Atlantic side of the island of Trinidad during the month of May 2017. Formaldehyde

92 (BDH, 36.5 wt. \% in water) was used in the seaweed pretreatment process. Acid treatment

93 experiments were performed using different concentrations of sulphuric acid (96.4\%) purchased

94 from J.T. Baker (USA). Calcium nitrate solution (1000ppm) used for Atomic Absorption 95 Spectroscopy (AAS) was purchased from Red analytical (USA). For the alkaline extraction 96 process, sodium carbonate (Scharlau, 99.9\%) was used. Food grade sodium alginate (purity $\geq$ 97 96\%) purchased from WillPowder (44145S, USA) was used as the analytical standard for High98 Performance Liquid Chromatography (HPLC), while commercial grade sodium alginate 99 purchased from Sigma-Aldrich (W201502, USA) was used for comparison studies. The buffer 100 solution used for HPLC was made using phosphoric acid (J.T. Baker, purity $>86 \%$ ) and sodium 101 hydroxide (J.T Baker, >99\%). For the purification process, $50 \%$ (w/v) alcohol (BDH, 94-96\% 102 ethanol and methanol) was used. For Nuclear Magnetic Resonance (NMR) analysis, deuterium 103 oxide (Sigma-Aldrich, purity $>99.9 \%$ ), triethylenetetraminehexaacetic acid (TTHA) (Sigma104 Aldrich, purity $\geq 98 \%$ ) and sodium deuteroxide (Sigma-Aldrich, purity 99\%) were used.

\subsection{Extraction process}

106

109 Figure 1 gives the overall extraction process for sodium alginate from Sargassum natans. The 110 process begins with seaweed pretreatment whereby bulk impurities such as debris (silt, sand, 111 plastics, and micro-organisms) are removed during continuous washing. After the washing step, 112 the Sargassum was preserved in $2 \%(\mathrm{w} / \mathrm{v})$ formaldehyde solution overnight using the same method 113 according to Fertah, Belfkira, Dahmane, Taourirte, and Brouillette (2017). Seaweed pretreatment 114 with formaldehyde was essential as the acid pretreatment step alone does not remove all the 115 phenolic compounds. The formaldehyde reacts with the phenolic compounds in the cell walls of 116 the seaweed allowing for enhanced product purity (Fertah, 2017; Wedlock \& Fasihuddin, 1990). 
117 After pretreatment, the solution was removed and the Sargassum was washed and dried for 48 118 hours at $40^{\circ} \mathrm{C}$.

119 Once the seaweed was completely dried, it was pulverized in an effort to increase surface area and 120 extraction rates (McHugh, 1987). The pulverized seaweed was sieved and a mean particle diameter

121 of approximately $505 \pm 5 \mu \mathrm{m}$ was calculated and used throughout acid pretreatment and alkaline 122 extraction experiments.

$123 \quad$ 2.2.2. Experimental and analytical methods

125 For acid pretreatment, alkaline extraction and sodium alginate precipitation samples were carried 126 out in triplicate while two control experiments were used for validation. All experimental errors 127 were analyzed by calculating both the standard deviation and coefficient of variance, while 128 statistical t-tests were used to test significance.

129 Atomic Absorption Spectroscopy (AAS) was used to quantify the amount of calcium released 130 during acid pretreatment. The conditions for AAS was as follows: calcium line: 422.7nm, slit 131 width: $1.2 \mathrm{~nm}$, acetylene/ nitrous oxide flame, $50 \mathrm{~mm}$ burner (width) operating at a height of $6 \mathrm{~mm}$. 132 Calcium standard solutions were made utilizing a $1000 \mathrm{ppm}$ calcium nitrate analytical solution. 133 The calibration curves plotted had an $\mathrm{R}^{2}$ value of 0.99 within a calibration range of $1-5 \mathrm{ppm}$.

134 High Performance Liquid Chromatography (HPLC) was used to quantify crude and purified 135 sodium alginate yields. A C18 stationary phase column $(150 \times 4.6 \mathrm{~mm}$ i.d., $3.5 \mu \mathrm{m})$ was used. The 136 mobile phase consisted of a buffer solution $(0.5 \mathrm{~mL}$ phosphoric acid) in $1 \mathrm{~L}$ deionized water at a 137 flow rate of $0.7 \mathrm{~mL} / \mathrm{min}$ at $25^{\circ} \mathrm{C}$, adjusted to $\mathrm{pH} 7.0$ with sodium hydroxide $(1 \mathrm{M})$. The system was 138 left to equilibrate for 30 minutes prior to sampling. A sample volume of $20 \mu \mathrm{L}$ was injected, and 139 sodium alginate was eluted at a retention time of $1.50 \pm 0.03$ minutes using a wavelength of $254 \mathrm{~nm}$. 140 Sodium alginate standards were made utilizing a $1 \mathrm{~g} / \mathrm{L}$ food grade alginate solution, and the 141 calibration curves had an $\mathrm{R}^{2}$ of 0.99 within the calibration range of $0.01-0.03 \mathrm{~g} / \mathrm{L}$.

\subsubsection{Acid pretreatment}

144 As shown in Figure 1, acid pretreatment follows seaweed pretreatment as an important step in the 145 conversion of calcium alginate into alginic acid. In brown seaweeds such as Sargassum, alginic 
146 acid is mainly present as the calcium salt of alginic acid although potassium, magnesium and 147 sodium salts may also be present (Bashford, Thomas, \& Woodward, 1950). As shown in Equation

$148 \mathrm{1}$, the insoluble calcium alginate, $\left(\mathrm{Ca}(\mathrm{Alg})_{2}\right)$, reacts with the sulphuric acid to form alginic acid, 149 (HAlg), and insoluble calcium sulphate, $\left(\mathrm{CaSO}_{4}\right)$

$$
\mathrm{Ca}(\mathrm{Alg})_{2}+\mathrm{H}_{2} \mathrm{SO}_{4} \rightarrow 2 \mathrm{HAlg}+\mathrm{CaSO}_{4}
$$

152 The calcium rate was calculated using the following equation:

$$
\text { Calcium Rate }=\frac{\text { mass of Calcium produced }(\mathrm{mg})}{\text { time taken }(\mathrm{hr}) \times \text { mass of seaweed used }(\mathrm{mg})}
$$

Acid pretreatment of Sargassum was performed according to procedures developed by Hernándezcarmona, McHugh, Arvizu-Higuera, and Rodríguez-montesinos (1998) and McHugh (1987). In an effort to quantify the efficiency of the acid pretreatment process, the effect of sulphuric acid

158 concentration, volume and temperature on calcium rate was investigated. $1 \pm 0.01 \mathrm{~g}$ of Sargassum 159 was reacted with sulphuric acid within a molar concentration range of 0.1-1M, an excess volume 160 range of 1:5-1:15 (Sargassum: $\mathrm{H}_{2} \mathrm{SO}_{4}$ ), and over a temperature range of $25-60^{\circ} \mathrm{C}$. Temperature 161 was monitored using a water bath (Julabo TW8, Germany). In order to promote mixing, the 162 samples were vortexed for 1 minute and reacted for 1 hour. After the reaction time had elapsed, 163 the samples were filtered using syringe filters $(0.45 \mu \mathrm{m})$, diluted and analyzed for calcium 164 concentration using AAS.

\subsubsection{Alkaline extraction}

167 After calcium alginate conversion during acid pretreatment, the insoluble alginic acid formed can 168 be converted into a soluble form as sodium alginate. As shown in Figure 1, the alginic acid can 169 be neutralized by the action of sodium carbonate according to Equation 3 (Hernández-carmona et 170 al., 1998):

$$
\mathrm{HAlg}+\mathrm{Na}^{+} \rightarrow \mathrm{NaAlg}+\mathrm{H}^{+}
$$

172 The crude yield of sodium alginate can be calculated using Equation 4: 
173 Yield $=\frac{\text { Concentration of Sodium Alginate Produced }(\mathrm{mg} / \mathrm{mL}) \times \operatorname{Volume}(\mathrm{mL})}{\text { Mass of Seaweed Used }(\mathrm{mg})}$

174 The conditions investigated during alkaline extraction were adapted from many authors (Basha, 175 Rekha, Letensie, \& Mensura, 2011; Davis, Ramirez, Mucci, \& Larsen, 2004; Fenoradosoa et al., 176 2010; Hernández-Carmona, McHugh, \& López-Gutiérrez, 1999; McHugh, 1987; Torres et al., 177 2007). Similar to Section 2.2.3, in an effort to investigate the efficiency of the extraction process, 178 the effect of sodium carbonate concentration, volume, temperature and reaction time was 179 investigated. Utilizing the best conditions from Section 2.2.3, $1 \pm 0.01 \mathrm{~g}$ of acid treated Sargassum 180 was reacted with sodium carbonate within a concentration range of $5-10 \%(\mathrm{w} / \mathrm{v})$, an excess volume 181 range of 1:5-1:15 (Sargassum: $\mathrm{Na}_{2} \mathrm{CO}_{3}$ ), over a temperature range of $25-75^{\circ} \mathrm{C}$, and reaction times 182 of 0.5-6 hours. After the associated reaction time had elapsed, the samples were centrifuged 183 (Thermo-IEC Centra MP4, USA) at 8000g and filtered. The filtrate was diluted and analyzed for 184 crude sodium alginate using HPLC.

\section{$\underline{\text { 2.3. Multistage alkaline extraction }}$}

In an effort to increase the overall crude sodium alginate yield from Sargassum, multistage alkaline extraction was carried out utilizing the most efficient conditions from both the acid pretreatment and alkaline extraction steps. Single batch stages were repeated for both steps as identified in Sections 2.2.3 and 2.2.4. After centrifugation was carried out at the end of the alkaline extraction step, the residual Sargassum was retrieved and extraction was repeated as a second stage. This multistage extraction process was repeated up to 5 stages, and the batch and cumulative crude

194 sodium alginate yields were estimated using HPLC.

\subsection{Multistage precipitation process}

198 In an effort to purify the crude sodium alginate extract, precipitation was adapted from the work 199 by McHugh (1987). $0.5 \mathrm{M} \mathrm{H}_{2} \mathrm{SO}_{4}$ was gradually added to the crude extract obtained, after the 200 multistage extraction process was carried out, until a $\mathrm{pH}$ of 2 was observed using a $\mathrm{pH}$ meter 201 (Thermo Scientific A211, USA). At this point the soluble crude sodium alginate was converted 
202 into insoluble alginic acid. The samples were centrifuged at $8000 \mathrm{~g}$ for 10 minutes, and the alginic 203 acid was separated. 15mls of alcohol was added to the alginic acid under constant stirring for 2 204 hours. After 2 hours elapsed, $5 \% \mathrm{Na}_{2} \mathrm{CO}_{3}$ was added to the mixture until the $\mathrm{pH}$ increased to 10 , 205 forming a thick sodium alginate gel. The samples were centrifuged, and the gel was collected, 206 placed into petri dishes, frozen at $-17^{\circ} \mathrm{C}$ for 24 hours, and freeze dried for 48 hours using an 207 Armfield vacuum freeze dryer (SB4, UK). The purified sodium alginate was then pulverized, and 208 the purity was analyzed using HPLC.

209 For the multistage precipitation process, this procedure was repeated up to 5 stages by re210 dissolving the purified sodium alginate after each subsequent stage. The true yield was calculated 211 using Equation 5:

$$
\text { True Yield }=\frac{\text { Mass of Purfied sodium alginate }}{\text { Mass of Seaweed Used (mg) }}
$$

\section{$213 \quad$ 2.5. Characterization}

IR spectra of the purified alginate samples were obtained using a Perkin Elmer Spectrum 400 FTIR/ FT-NIR spectrometer with a universal ATR sampling accessory. The spectra were recorded in the range of $650-4000 \mathrm{~cm}^{-1}$ with a $4 \mathrm{~cm}^{-1}$ resolution. The IR-laser wavenumber was set at 15780.00 $\mathrm{cm}^{-1}$, OPD velocity of $0.20 \mathrm{~cm} / \mathrm{sec}$ and J-stop size of $8.94 \mathrm{~mm}$.

\subsubsection{Nuclear magnetic resonance (NMR)}

224 The samples for NMR analysis was done according to ASTM F2259 - 10 (2012). Firstly the 225 alginate was depolymerized via acid hydrolysis. $100 \mathrm{mLs}$ of $0.1 \%(\mathrm{w} / \mathrm{v})$ alginate solution was 226 prepared and the $\mathrm{pH}$ was adjusted to 5.6 using $0.1 \mathrm{M}$ hydrochloric acid. The alginate solution was 227 placed in a water bath at $100^{\circ} \mathrm{C}$ for 1 hour. The $\mathrm{pH}$ was re-adjusted to 3.8 with $0.1 \mathrm{M}$ hydrochloric 228 acid and replaced into the water bath at $100^{\circ} \mathrm{C}$ for 30 minutes. The $\mathrm{pH}$ was then neutralized to 7 229 with $0.1 \mathrm{M}$ sodium hydroxide and the sample was freeze-dried overnight. The alginate sample was then dissolved in $5 \mathrm{~mL}$ of $99.9 \% \mathrm{D}_{2} \mathrm{O}$ and freeze-dried again. 10-12 $\mathrm{mg}$ of the sample was then 
231 dissolved in $1 \mathrm{~mL}$ of $99.9 \% \mathrm{D}_{2} \mathrm{O} .0 .7 \mathrm{~mL}$ of the alginate was added to a NMR tube along with

$23240 \mu \mathrm{L}$ of $0.15 \mathrm{M}$ TTHA (triethylenetetraminehexaacetic acid). The $\mathrm{pH}$ of the TTHA was adjusted

233 to 5.5 using sodium deuteroxide ( $\mathrm{NaOD}$ ). The TTHA was used as a chelator to minimize traces of

234 divalent cations interacting with the alginate. The NMR spectra were recorded on a NMR

235 spectrometer (Bruker AVANCE ${ }^{\mathrm{TM}} 600 \mathrm{MHz}$ ) operating at $80^{\circ} \mathrm{C}$ with the sample spinning at 20

$236 \mathrm{~Hz}$ using a standard one-dimensional pulse program, a frequency of $600 \mathrm{MHz}$, a spectral window

237 of $6 \mathrm{kHz}$ with a pulse angle of $90^{\circ}, 2$ seconds relaxation delay and acquisition time of 5.453 seconds

238 collecting 65536 data points. 64 scans were accumulated for signal averaging. The chemical shifts

239 of the anomeric proton signals were done according to ASTM-F2259-10 method with A (guluronic

240 acid anomeric proton) at around $5.2 \mathrm{ppm}$; B1 (H-5 proton of the central guluronic acid residue in

241 a GGM triad) at $4.78 \mathrm{ppm}$; B2 (H-5 proton of the central guluronic acid residue in a MGM triad)

242 at $4.75 \mathrm{ppm}$; B3 ( anomeric proton of the mannuronic acid residue neighboring a mannuronic

243 acid) at $4.71 \mathrm{ppm}$; B4 (anomeric proton of the mannuronic acid residue neighboring a guluronic

244 acid) at $4.68 \mathrm{ppm}$ and $\mathrm{C}$ (guluronic acid proton 5) at $4.48 \mathrm{ppm}$.

\section{Results and discussion}

249 The small amounts of polyphenolic residues present in alginates make them strongly fluorescent 250 (Fertah, 2017). The spectrum produced (Figure 2) gave a strong and sharp band at $1610 \mathrm{~cm}^{-1}$ as 251 this represents the strong carboxylate asymmetric stretching vibration. The absorption band at $2521395 \mathrm{~cm}^{-1}$ shows the weaker COO symmetric stretching vibration of the carboxylate group. The 253 characteristic peaks obtained in this study correlates closely with previous studies (Bi, Mahmood, 254 Arman, Taj, \& Iqbal, 2007; Fenoradosoa et al., 2010; Fertah, 2017; Latifi, Sadegh Nejad, \& 255 Babavalian, 2015; Papageorgiou et al., 2010; Rhein-Knudsen, Ale, Ajalloueian, \& Meyer, 2017b) 256 giving strong bands at around 1600 and $1400 \mathrm{~cm}^{-1}$ indicative of the asymmetric and symmetric 257 vibrations. The presence of these carboxylate groups further show that the alginate was extracted 258 at alkaline $\mathrm{pH}$ in the form of a sodium alginate salt (Rhein-Knudsen et al., 2017b). Furthermore, 259 the spectra for sodium alginate produced from the Sargassum was similar to the sodium alginate 
260 from the commercial brand, and resembles the finger print region $\left(1600-1400 \mathrm{~cm}^{-1}\right)$. Hence, this

261 further confirms the presence of sodium alginate in the extracted samples.

262 3.2. Nuclear magnetic resonance (NMR)

263

264 Figure 3(A) shows the NMR spectra of the sodium alginate sample extracted from the Sargassum 265 natans with the peaks representing the anomeric and other protons at varying carbon positions on 266 the uronic acid sequence. The assignment of the peaks obtained in the spectra are slightly different 267 from those in the ASTM standard used. These differences in the chemical shifts obtained in the 268 alginate extract with the ASTM standard F2259 - 10 (2012) can be attributed to the presence of 269 trace elements of metal ions in the alginate extracted and differences in the chemical composition 270 and properties such as molecular weight. The presence of the metal ions (calcium) causes line 271 broadening and selective loss of signal intensity.

272 However, from Figure 3(B), the chemical shifts of the signature protons for the alginate extracted 273 from Sargassum natans and commercial brand Sigma overlay precisely, confirming that the 274 polysaccharide extracted from the Sargassum natans was in fact alginate.

275 The block structure and $\mathrm{M} / \mathrm{G}$ ratio was calculated according to the calculation proposed in the 276 ASTM standard F2259 - 10 (2012). The M/G ratio (0.51) of the alginate extracted in this study 277 correlates closely to the M/G ratio of the alginate extracted from Sargassum natans, 0.47 (Rhein278 Knudsen et al., 2017b). The M/G ratio of this sodium alginate from Sargassum natans can be 279 elucidated to lie within the range of the Sargassum genus from Table 1 having enriched guluronic 280 acid content. The commercial brand Sigma, has a high M/G ratio compared to Sargassum and this 281 was not unexpected as commercial brands extracted from Ascophyllum and Laminaria range from 2821.2 to 2.2 (Grasdalen, 1983). The uronic acid sequence highly influences the ability of the alginate 283 to form gels (Penman \& Sanderson, 1972). M-blocks show flexible and linear conformations 284 while $\mathrm{G}$ blocks have rigid structural conformations giving rise to a distinct stiffness of the 285 molecular chains (Avella et al., 2007). Gel formation occurs mainly as a result of the formation of 286 enriched GG junction zones. Alginates that possess a low M/G ratio give hard and brittle gels while 287 those with a high M/G ratio form soft and elastic gels (Penman \& Sanderson, 1972). Hence this 288 extracted alginate possesses a high guluronic acid content of $66 \%$ (standard deviation $\pm 1 \%$ ) and 289 will most likely form strong gels. 


\section{$\underline{\text { 3.3. Effect of } \mathrm{H}_{2} \mathrm{SO}_{4} \text { concentration and excess volume on calcium rate }}$}

The acid pre-treatment process is very important since it converts all the insoluble salts that remain

294 in the algal matter after washing, into alginic acid which is converted to sodium alginate upon 295 alkaline treatment (A. Haug, 1964). Insight into acid pretreatment conditions have not been looked 296 at in any precise or scientific nature in previous studies (Davis et al., 2004; Fenoradosoa et al., 297 2010; Larsen et al., 2003; McHugh, 1987; Rhein-Knudsen et al., 2017a; Torres et al., 2007). 298 Furthermore, calcium rate gives a measure of the extent of alginic acid conversion and has not been reported by any previous research. Acid pre-treatment is typically done with a dilute mineral acid usually sulphuric acid or hydrochloric acid (A. Haug, 1964; McHugh, 1987). In this study, sulphuric acid was chosen due to its lower $\mathrm{pK}_{\mathrm{a}}(-10)$ compared to hydrochloric acid (-7) (Lide, 2005). Hence, sulphuric acid would provide higher alginic acid conversion.

Figure 4(A) shows the effect of increased molar concentration on the total amount of calcium released (Equation 2). It can be shown from Figure 4(A) that as the molar concentration of the sulphuric acid increases from $0.1 \mathrm{M}$ to $0.5 \mathrm{M}$, there was a general increase in the calcium rate with a maximum rate of $0.26 \mathrm{mg}$ calcium/(mg.seaweed.h) being recorded. However, it was observed that as the molar concentration increased above $0.5 \mathrm{M}$, the calcium rate decreased to $0.17 \mathrm{mg}$ calcium/(mg.seaweed.h). Sulphuric acid is a strong acid and in aqueous solution fully dissociates into $\left[\mathrm{H}^{+}\right]$and $\left[\mathrm{SO}_{4}{ }^{2-}\right]$. High acid concentration can lead to degradation of the cell walls within the Sargassum structure. These cell walls are comprised of glucans which are polysaccharides composed of glucose, and at low $\mathrm{pH}$ these glucans can be preferentially hydrolyzed (Yanagisawa,

312 Kawai, \& Murata, 2013). As such, as the $\mathrm{pH}$ decreases, the hydrolysis reaction competes with the 313 calcium conversion process. Hence, it can be elucidated that as the molar concentration of the acid 314 increases, the rate of hydrolysis increases and as such a decrease in the calcium rate was observed. 315 Although the effects of acid hydrolysis were observed at $1 \mathrm{M}$, the overall calcium rate was 1.4 316 times higher than that at $0.1 \mathrm{M}$, showing that the calcium conversion process favors a higher acid 317 concentration.

318 Figure 4(B), which shows that as the acid volume increased, the calcium rate increased, following 319 the same general trend as Figure 4(A). These results can be explained as a larger volume of acid 
320 added to the seaweed results in more $\left[\mathrm{H}^{+}\right]$ions being readily available, increasing the calcium ions 321 exchanged and the amount of alginic acid formed.

\section{3.4. Effect of temperature on calcium rate}

324 The effect of temperature on calcium rate is an important parameter that has not been investigated 325 fully in previous work done on acid pretreatment. $0.5 \mathrm{M}$ sulphuric acid at an excess volume of 1:15, 326 were used to conduct experiments to analyze the temperature for optimum $\mathrm{Ca}^{2+}$ ions liberation.

327 Figure $4(\mathrm{C})$ relates the relationship between the calcium rate and the temperatures tested $\left(25^{\circ} \mathrm{C}\right.$, $32830^{\circ} \mathrm{C}, 40^{\circ} \mathrm{C}, 50^{\circ} \mathrm{C}$, and $\left.60 \pm 0.1^{\circ} \mathrm{C}\right)$. It was observed that as the temperature increases, the calcium 329 rate also increases, with a maximum temperature recorded at $40^{\circ} \mathrm{C}$. An increase in temperature 330 allows for increased $\left[\mathrm{H}^{+}\right]$ions and therefore increased calcium rate. Similar acid pretreatment 331 results have been reported by (McHugh, 1987) as degradation of the alginate occurs with most 332 species of seaweed at temperatures beyond $50^{\circ} \mathrm{C}$.

333 The results suggest that $40^{\circ} \mathrm{C}$ was the optimum temperature for acid treatment at $0.5 \mathrm{M}$ sulphuric 334 acid using 1:15 excess volume. A Student's T-test $(\mathrm{p}=0.05)$ was also done in order to assess 335 whether the averages at $50^{\circ} \mathrm{C}$ and $60^{\circ} \mathrm{C}$ were significantly different from $40^{\circ} \mathrm{C}$. The results showed 336 that they were insignificant and therefore confirmed that $40^{\circ} \mathrm{C}$ was the optimum temperature.

\subsection{Effect of $\mathrm{Na}_{2} \mathrm{CO}_{3}$ concentration and excess volume on sodium alginate}

Previous research into alkaline extraction (Basha et al., 2011; Davis et al., 2004; Fenoradosoa et al., 2010; Hernández-Carmona et al., 1999; McHugh, 1987; Torres et al., 2007) have been carried out but no specific operating ranges have been given.. Thus, it was important that conditions be investigated to understand its effect on sodium alginate yield, and to find the desired conditions that maximizes the sodium alginate yield obtained from Sargassum natans.

345 From Figure 5(A), it was observed that crude sodium alginate yield (Equation 4) decreased by 346 more than $50 \%$ as the alkaline concentration increased above $5 \%$. The $5 \% \mathrm{Na}_{2} \mathrm{CO}_{3}$ concentration 347 gave the highest yield of crude sodium alginate with a value of $6.08 \%$ whereas $10 \% \mathrm{Na}_{2} \mathrm{CO}_{3}$ gave 348 the lowest yield at a value of $1.65 \%$. A Student's T-test $(\mathrm{p}=0.05)$ was performed for both $1 \mathrm{~g}$ : $34910 \mathrm{~mL}$ and $1 \mathrm{~g}: 15 \mathrm{~mL}$ at $7 \%$ sodium carbonate. The results indicated that they were both statistically 
significant. Another Student's t-test $(\mathrm{p}=0.05)$ was done for all 3 excess volumes at $10 \%$ sodium carbonate. However, the results showed that they were not statistically significant.

Alkaline degradation at high concentrations results in the formation of monocarboxylic and dicarboxylic acids (Niemelä \& Sjöström, 1985), and hence can explain the decrease in the yields of sodium alginate extracted from Sargassum natans observed at $7 \%$ and $10 \% \mathrm{Na}_{2} \mathrm{CO}_{3}$. The $\mathrm{pH}$ of the aqueous solutions of $7 \%$ and $10 \% \mathrm{Na}_{2} \mathrm{CO}_{3}$ are of moderate alkalinity $(\mathrm{pH}>10)$ (Kroschwitz \& Seidel, 2004) and thus promotes degradation of the alginate significantly (A. Haug, 1964; Moen, 1997). Furthermore, alkalis can react with alginates causing $\beta$-elimination of the glycoside bond which reduces the yield of the intact polysaccharide. Also, effects of this degradation process can be more pronounced at $\mathrm{pH}>10$ (Arne Haug, Larsen , \& Smidsron 1963).

Figure 5(B) shows the general trend that as the alkali volume increased, crude sodium alginate yield increased, with the highest yields being reported with the highest volumes used. Similar to

362 the acid pretreatment results observed in Section 3.3, an increase in the volume of alkali added 363 increases the neutralization effect that occurs between alginic acid and $\mathrm{Na}_{2} \mathrm{CO}_{3}$, and also allows 364 for better solubilisation of the extracted crude sodium alginate. Hence, a greater yield of extraction would be obtained. Using alkali volumes of $1: 10$ and $1: 15$ at concentrations of $7 \%$ and $10 \%$ $\mathrm{Na}_{2} \mathrm{CO}_{3}$ gave low yields further indicating that $\mathrm{pH}$ has a pronounced effect on the conversion of the alginic acid. Hence, from the results shown in Figures 5(A) and (B) a low concentration of $\mathrm{Na}_{2} \mathrm{CO}_{3}$ was favorable for the alkaline extraction process.

\subsection{Effect of temperature and reaction time on sodium alginate vield}

371 From Figure 5(C), it was observed that the crude sodium alginate yield increased over the 372 temperature range of $25^{\circ} \mathrm{C}$ to $65^{\circ} \mathrm{C}(7 \%$ to $15 \%)$ utilizing a concentration of $5 \% \mathrm{Na}_{2} \mathrm{CO}_{3}$, at an 373 excess of 1:15, and an extraction time of 2 hours. Furthermore, a maximum yield was found at $65^{\circ} \mathrm{C}$ and this was recorded as the optimum temperature. These results correlated well with Torres et al. (2007) who reported an optimum temperature at $60^{\circ} \mathrm{C}$ in the extraction of sodium alginate from Sargassum vulgare. However, there was an observed decrease in the yield between $65^{\circ} \mathrm{C}$ and

$37775^{\circ} \mathrm{C}$ which can be attributed to the higher temperatures leading to the breakdown of uronic acid 378 chains and consequently lower viscosities for the sodium alginate. Whistler and BeMiller (1959) 379 reported that alginates are readily degraded by alkaline solutions at high temperatures resulting in 
380 the formation of new dicarboxylic saccharinates. It could be quite possible that this degradation 381 reaction explains the decrease in sodium alginate yield at $75^{\circ} \mathrm{C}$.

382 Reaction time plays an integral role in the alkaline extraction and there has been no thorough 383 analysis done to investigate how sodium alginate yields from Sargassum trend over a range of 384 reaction times. Figure 5(D) shows the crude sodium alginate yield obtained when the seaweed 385 was reacted over different time periods at the optimized conditions $\left(65^{\circ} \mathrm{C}, 1: 15\right.$ excess volume, $5 \%$ $\left.386 \mathrm{Na}_{2} \mathrm{CO}_{3}\right)$. A Student's T-test $(\mathrm{p}=0.05)$ was carried out on the data above (Figure $\left.5 \mathrm{D}\right)$ and it was 387 found that for all reaction times investigated, the yields reported were not significantly different. 388 The reasoning behind this could be that the extraction equilibria associated with the sodium alginate conversion reaction occurs rapidly during the first hour of extraction, and hence, the maximum amount of sodium alginate liberated was accounted for within this particular time frame. During a reaction, the mass transfer resistance is often reduced allowing for rapid equilibrium (Klaewkla, Arend, \& Hölderich, 2011). From Figure 5(D), the highest crude yield reported was

$39315 \%$ after one extraction stage. It can be elucidated from the results, that increased reaction time 394 does not affect the overall crude sodium alginate obtained from Sargassum natans.

\subsection{Effect of multistage extraction and multistage precipitation on sodium} alginate yield and purity

Conventional extraction and precipitation of sodium alginate from seaweed is usually based on single stage batch processing. Previous research (Table 2) has reported results based on one purification stage with very little analysis on purity. The objective of the extraction process was to recover as much alginate as possible so as to obtain a high yield. In order for complete extraction to occur, a concentration gradient must be established between the concentration of solute at the surface of the solid particles and that in the bulk solution.

In single stage extraction, as the phases approach equilibrium, the gradient ceases and hence, the 405 overall rate of extraction decreases (Brennan, Grandison, \& Lewis, 2006). After one stage, the seaweed may still contain a significant amount of alginate and can be recovered via further extraction of the solute with fresh solvent. The rate of diffusion determines the length of time

408 needed to achieve equilibrium between phases (Toledo, 1991). In this solid-liquid extraction, the 409 sodium carbonate must diffuse into the cell walls of the seaweed in order for neutralization to 
410 occurs, and the alginate must diffuse out of the 'carbonate-saturated seaweed' into the bulk 411 solution. However, this cannot be achieved fully using single stage extraction and hence the need 412 for multistage extraction (Berk, 2009).

413 Multistage extraction and precipitation of sodium alginate from Sargassum natans has never been 414 explored as a process for maximizing yield and purity. This study demonstrates the optimum 415 number of extraction and purification stages to maximize both yield and purity of the sodium 416 alginate at the optimum conditions reported previously; $5 \% \mathrm{Na}_{2} \mathrm{CO}_{3}, 1: 15$ excess volume, at a 417 temperature of $65^{\circ} \mathrm{C}$ and a reaction time of 2 hours.

418 From Table 2, it was found that after one extraction stage, the crude sodium alginate yield obtained 419 was $15 \%$. After the first extraction stage, it was assumed that the seaweed residue still contains 420 crude sodium alginate that can be extracted. Upon a second extraction stage, it was found that the 421 residual alginate found accounted for a crude yield of $2 \%$. By reacting the residue with fresh 422 solvent, a new concentration gradient can be established allowing for increased extraction and an 423 overall cumulative yield of $17 \%$. These findings correlate well with past research utilizing 424 multistage extraction techniques such as; in the extraction of polyphenols from olive leaves, the 425 extraction yield increased to more than $50 \%$ after 3 stages compared to single stage extraction 426 (Stamatopoulos, Chatzilazarou, \& Katsoyannos, 2014). Furthermore, in the extraction of protein 427 from Jatropha curcas seeds, the recovery increased from 35\% to $73 \%$ after 4 stages (Lestari, 428 Mulder, \& Sanders, 2010).

429 However, it was observed that beyond 2 stages the crude yield was very low $(<1 \%)$ and it was no 430 longer feasible to carry out extraction. This can be explained whereby the net molar transport stops 431 when equilibrium was reached between the phases. As a result the chemical potential of the 432 extractable solute was the same in all phases (Berk, 2009). Hence, after two extraction stages, 433 equilibrium was attained and all the available alginate within the seaweed was recovered. Thus, it 434 can be shown that multistage extraction can in fact be used to maximize the crude yield of sodium 435 alginate from Sargassum.

436 In an effort to improve the purity of the sodium alginate extracted from Sargassum, multistage 437 precipitation was carried out utilizing the crude extract obtained from 2 extraction stages. The 438 freeze-dried sodium alginate obtained after the first purification stage was re-dissolved, and the 439 precipitation process was repeated for each subsequent stage up to 5 stages. 
440 After the first precipitation stage, the true yield and purity was found to be $19 \%$ and $67 \%$ 441 respectively. From Table 2, it can be shown that as the number of precipitation stages increases, 442 the yield decreases while the purity increases. From stage to stage, the equilibrium changes and 443 this can result in lower yields observed in each subsequent stage. The reducing yields can be 444 attributed to imperfect separation of the alginate from the impurities which may result in the 445 discarding of fractions that are deemed insufficiently pure. Also, as more impurities are removed, 446 according to Equation 5, the true yield can be expected to decrease. However, as the number 447 stages increases, the impurity removal rate increases thus allowing for enhanced sodium alginate 448 purity.

449 The true yield of sodium alginate reported in this study correlates well with that of other Sargassum 450 sources (Table 2). Hence, alginate yields obtained in this study can be postulated to lie within the 451 range for the Sargassum genus. It should be noted that the true yield found in this study was lower 452 than the alginate extracted from other commercial algal species such as Ascophyllum nodosum, 453 Lessonia nigrescens, Macrocytis pyrifera, Laminaria spp, Durvillea willana and Marginariella 454 boryana, which reports yields of up to $61 \%$ of their dry weight (Draget et al., 2005; Panikkar \& 455 Brasch, 1996; Rinaudo, 2007). However, the true yield value of 19\% was not surprising as 456 McHugh (2003) states that Sargassum usually gives sodium alginate that has borderline quality 457 and of a low yield. Nevertheless, through multistage precipitation, the purity was relatively high 458 and found to increase from $67 \%$ to $74 \%$.

459 Also, it can be elucidated that the differences in the yields reported in literature can be due to the 460 fact that the extraction process was carried out using different Sargassum species. Additionally, 461 the extraction yield can be affected by the period and place of collection of the seaweed. 462 Furthermore, the low yields reported in literature could have occurred as the extraction for that 463 particular species may not have been carried out at the ideal conditions. Therefore, it can be 464 elucidated a more complete extraction of sodium alginate can be attained using multistage extraction and multistage precipitation rather than single stage extraction and precipitation. 
468 Optimization has never been used as a method for improving the sodium alginate yield and purity 469 from Sargassum natans. Process optimization is an important tool that can be used to maximize 470 efficiency, by setting specified parameters without violating constraints.

471 Figure 6(A) shows the relationship between purity and yield between subsequent stage 472 precipitations illustrated in Table 2. The equations for the purity and yield are as follows:$$
\mathrm{P}=-0.80032 \mathrm{~N}^{2}+6.4042 \mathrm{~N}+61.28534
$$

475 Where P - Purity (\%), Y - Yield (\%), and N - Number of stages.

476 By maximizing Equation 6 as shown in the Equation 8, the maximum purity was found to be $47774 \%$ at four stages with a corresponding yield of $10 \%$.

$$
\frac{\mathrm{dP}}{d N}=-0.80032(2) \mathrm{N}+6.4042=0
$$

The graph in Figure 6 (A) clearly shows that a compromise between maximum purity and yield can be found at $2 \leq \mathrm{N} \leq 3$. To obtain a better understanding of the model and estimate of the number of stages required for high purity and yield, multi-objective optimization was used. In this 482 multi-objective optimization problem, the objectives are to maximize the functions for purity and 483 yield, and therefore determine the optimum number of stages required.

484 The 'gamultiobj' function in the Global Optimization Toolbox in MATLAB R2017b was utilized. 485 In MATLAB, the objective functions were set up to minimize $-\mathrm{P}$ and $-\mathrm{Y}$ within the constraint of $4861 \leq N \leq 5$. It should be noted that the 'gamultiobj' function only considers minimization problems 487 and hence, the equivalent was to minimize $-\mathrm{P}$ and $-\mathrm{Y}$.

488 The MATLAB model predicts several conditions for which the optimized objective functions fit, 489 and the results are graphically shown in Figure 6(B). It is evident that high purity and high yield 490 occurs at Stage 3 and this is in accordance with the estimated number of stages from Figure 6(A). 491 If the optimum number of stages are used, the purity and yield should lie within the ranges of 71 $492-74 \%$ and $12-16 \%$ respectively. 


\section{Conclusions}

496 This study provides optimized process conditions for the multistage sodium alginate extraction

497 and purification process, and provides a novel optimized model for maximizing purity and yield

498 of extracted sodium alginate from Sargassum natans.

499 For acid pretreatment a maximum calcium rate of $0.26 \mathrm{mg}$ calcium/(mg.seaweed.h) was found 500 utilizing a concentration of $0.5 \mathrm{M} \mathrm{H}_{2} \mathrm{SO}_{4}$, a 1:15 excess volume, and at a temperature of $40^{\circ} \mathrm{C}$. Also, 501 for alkaline extraction a maximum crude yield of $15 \%$ was reported using a concentration of 5\% $502 \mathrm{Na}_{2} \mathrm{CO}_{3}$, a $1: 15$ excess volume, at a temperature of $65^{\circ} \mathrm{C}$, and a reaction time of 2 hours. 503 Furthermore, it was found that at high acid and alkali concentrations, degradation occurred 504 resulting in low alginic acid conversion and low crude yields of sodium alginate respectively.

505 Multistage extraction proved that 2 stages were needed in order to maximize the cumulative crude 506 yield of sodium alginate to $17 \%$, while multistage precipitation showed that a true yield and purity 507 of $19 \%$ and $67 \%$ respectively can be obtained after one stage. Optimization of the multistage 508 precipitation process was investigated, and the results showed that a compromise between 509 maximum sodium alginate yield and purity can be obtained after 3 stages; $12-16 \%$ and $71-74 \%$ 510 respectively. Furthermore, characterization of the sodium alginate from Sargassum natans was 511 carried out using FTIR with characteristic peaks obtained confirming the presence of sodium 512 alginate, giving the carboxylate asymmetric stretching vibration at $1610 \mathrm{~cm}^{-1}$ and symmetric 513 vibration at $1395 \mathrm{~cm}^{-1}$. Also NMR characterization gave insight into the uronic acid structure of 514 the extracted sodium alginate, giving an $\mathrm{M} / \mathrm{G}$ ratio of 0.51 with a high guluronic acid content of $51566 \%$.

516 Hence, the results of this study provides a novel optimized process that can be applied to other 517 alginate systems (brown seaweeds). This new process can be fundamentally important as alginates 518 are becoming increasingly attractive within the healthcare, pharmaceutical, environmental and 519 food industries, where an optimization system can lower costs and provide a higher product quality 520 and yield. Furthermore, this study provides the foundation for future work into the fabrication of 521 films from sodium alginate extracted from Sargassum natans, for use as an alternative to 522 conventional plastics for packaging and encapsulation. 


\section{Acknowledgments}

525 The authors would like to thank the NMR and FTIR units at the Department of Chemistry at The University of the West Indies for FTIR and NMR analysis. This research did not receive any specific grant from funding agencies in the public, commercial, or not-for-profit sectors.

\section{References}

Almeida, H., Amaral, M. H., Lobão, P., \& Lobo, J. M. S. (2014). In situ gelling systems: a strategy to improve the bioavailability of ophthalmic pharmaceutical formulations. Drug Discovery Today, 19(4), 400-412.

Avella, M., Pace, E. D., Immirzi, B., Impallomeni, G., Malinconico, M., \& Santagata, G. (2007). Addition of glycerol plasticizer to seaweeds derived alginates: Influence of microstructure on chemical-physical properties. Carbohydrate Polymers, 69(3), 503-511.

Axpe, E., \& Oyen, M. L. (2016). Applications of Alginate-Based Bioinks in 3D Bioprinting. International Journal of Molecular Sciences, 17(12), 1976.

Barzegari, A., \& Saei, A. A. (2012). An Update to Space Biomedical Research: Tissue Engineering in Microgravity Bioreactors. BioImpacts : BI, 2(1), 23-32.

Basha, N. S., Rekha, R., Letensie, A., \& Mensura, S. (2011). Preliminary Investigation on Sodium Alginate Extracted from Sargassum Subrepandum of Red Sea of Eritrea as Tablet Binder. 2011, 3(3), 10.

Bashford, L. A., Thomas, R. S., \& Woodward, F. N. (1950). Manufacture of algal chemicals. U. Production of alginates from brown marine algae. Journal of the Society of Chemical Industry, 69(11), 337-343.

Berk, Z. (2009). Food Process Engineering and Technology.

Bi, F., Mahmood, S. J., Arman, M., Taj, N., \& Iqbal, S. (2007). Physicochemical characterization and ionic studies of sodium alginate from Sargassum terrarium (brown algae). Physics and Chemistry of Liquids, 45(4), 453-461.

Brennan, J. G., Grandison, A. S., \& Lewis, M., J. (2006). Separations in Food Processing. In Food Processing Handbook.

Calafiore, R., \& Basta, G. (2014). Clinical application of microencapsulated islets: Actual prospectives on progress and challenges. Advanced Drug Delivery Reviews, 67-68, 84-92.

Carella, S., Maruccia, M., Fino, P., \& Onesti, M. G. (2013). An Atypical Case of Henoch-Shönlein Purpura in a Young Patient: Treatment of the Skin Lesions with Hyaluronic Acid-based Dressings. In Vivo, 27(1), 147-151.

Chen, L., Shen, R., Komasa, S., Xue, Y., Jin, B., Hou, Y., . . . Gao, J. (2017). Drug-Loadable Calcium Alginate Hydrogel System for Use in Oral Bone Tissue Repair. International Journal of Molecular Sciences, 18(5), 989.

Davis, T. A., Llanes, F., Volesky, B., \& Mucci, A. (2003). Metal Selectivity of Sargassum spp.

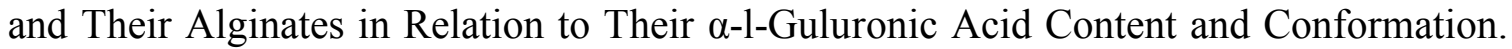
Environmental Science \& Technology, 37(2), 261-267.

Davis, T. A., Ramirez, M., Mucci, A., \& Larsen, B. (2004). Extraction, isolation and cadmium binding of alginate from Sargassum spp. Journal of Applied Phycology, 16(4), 275-284. 
Donati, I., Vetere, A., Gamini, A., Coslovi, A., Campa, C., \& Paoletti, S. (2003). GalactoseSubstituted Alginate: Preliminary Characterization and Study of Gelling Properties. Biomacromolecules, 4(3), 624-631.

Draget, K. I., Smidsrød, O., \& Skjåk-Bræk, G. (2005). Alginates from Algae. In Biopolymers Online: Wiley-VCH Verlag GmbH \& Co. KGaA

Fenoradosoa, T. A., Ali, G., Delattre, C., Laroche, C., Petit, E., Wadouachi, A., \& Michaud, P. (2010). Extraction and characterization of an alginate from the brown seaweed Sargassum turbinarioides Grunow. Journal of Applied Phycology, 22(2), 131-137.

Fertah, M. (2017). Chapter 2 - Isolation and Characterization of Alginate from Seaweed A2 Venkatesan, Jayachandran. In S. Anil \& S.-K. Kim (Eds.), Seaweed Polysaccharides (pp. 11-26): Elsevier

Fertah, M., Belfkira, A., Dahmane, E. m., Taourirte, M., \& Brouillette, F. (2017). Extraction and characterization of sodium alginate from Moroccan Laminaria digitata brown seaweed. Arabian Journal of Chemistry, 10(Supplement 2), S3707-S3714.

Grant, G. T., Morris, E. R., Rees, D. A., Smith, P. J. C., \& Thom, D. (1973). Biological interactions between polysaccharides and divalent cations: The egg-box model. FEBS Letters, 32(1), 195-198.

Grasdalen, H. (1983). High-field, 1H-n.m.r. spectroscopy of alginate: sequential structure and linkage conformations. Carbohydrate Research, 118, 255-260.

Haug, A. (1964). Composition and Properties of Alginates: Norwegian Institute of Seaweed Research.

Haug, A., Larsen , B., \& Smidsron , O. (1963). The Degradation of Alginates at Different pH values. Acta Chem Scand.

Hegarty, S. V., O'Keeffe, G. W., \& Sullivan, A. M. (2014). Neurotrophic factors: from neurodevelopmental regulators to novel therapies for Parkinson's disease. Neural Regeneration Research, 9(19), 1708-1711.

Hernández-carmona, G., McHugh, D. J., Arvizu-Higuera, D. L., \& Rodríguez-montesinos, Y. E. (1998). Pilot plant scale extraction of alginate from Macrocystis pyrifera. 1. Effect of preextraction treatments on yield and quality of alginate. Journal of Applied Phycology, 10(6), 507-513.

Hernández-Carmona, G., McHugh, D. J., \& López-Gutiérrez, F. (1999). Pilot plant scale extraction of alginates from Macrocystis pyrifera. 2. Studies on extraction conditions andmethods of separating the alkaline-insoluble residue. Journal of Applied Phycology, 11(6), 493-502.

Klaewkla, R., Arend, M., \& Hölderich, W. (2011). A Review of Mass Transfer Controlling the Reaction Rate in Heterogeneous Catalytic Systems.

Kroschwitz, J. I., \& Seidel, A. (2004). Kirk-Othmer encyclopedia of chemical technology. Hoboken, N.J.: Wiley-Interscience.

Larsen, B., Salem, D. M. S. A., Sallam, M. A. E., Mishrikey, M. M., \& Beltagy, A. I. (2003). Characterization of the alginates from algae harvested at the Egyptian Red Sea coast. Carbohydrate Research, 338(22), 2325-2336.

Latifi, A. M., Sadegh Nejad, E., \& Babavalian, H. (2015). Comparison of Extraction Different Methods of Sodium Alginate from Brown Alga Sargassum sp. Localized in the Southern of Iran. Journal of Applied Biotechnology Reports; Vol 2 No 2: Spring 2015.

Lee, K. Y., \& Mooney, D. J. (2012). Alginate: properties and biomedical applications. Progress in polymer science, 37(1), 106-126. 
Lestari, D., Mulder, W., \& Sanders, J. (2010). Improving Jatropha curcas seed protein recovery by using counter current multistage extraction. Biochemical Engineering Journal, 50(1), 1623.

Lide, D. R. (2005). CRC Handbook of Chemistry and Physics.

McHugh, D. J. (1987). Production and Utilization of Production from Commericial Seaweeds. FOA Fisheries Technical Paper 288. Rome: Food and Agriculture Organization of the United Nations.

McHugh, D. J. (2003). A Guide to the Seaweed Industry. FAO Fisheries Technical Paper. Rome: Food and Agriculture Organization of the United Nations.

Moen, E. (1997). Biological degradation of brown seaweeds.

Niemelä, K., \& Sjöström, E. (1985). Alkaline degradation of alginates to carboxylic acids. Carbohydrate Research, 144(2), 241-249.

Panikkar, R., \& Brasch, D. J. (1996). Composition and block structure of alginates from New Zealand brown seaweeds. Carbohydrate Research, 293(1), 119-132.

Papageorgiou, S. K., Kouvelos, E. P., Favvas, E. P., Sapalidis, A. A., Romanos, G. E., \& Katsaros, F. K. (2010). Metal-carboxylate interactions in metal-alginate complexes studied with FTIR spectroscopy. Carbohydrate Research, 345(4), 469-473.

Penman, A., \& Sanderson, G. R. (1972). A method for the determination of uronic acid sequence in alginates. Carbohydrate Research, 25(2), 273-282.

Rajesh, A. M., Bhatt, S. A., Brahmbhatt, H., Anand, P. S., \& Popat, K. M. (2015). Taste masking of ciprofloxacin by ion-exchange resin and sustain release at gastric-intestinal through interpenetrating polymer network. Asian Journal of Pharmaceutical Sciences, 10(4), 331340.

Rhein-Knudsen, N., Ale, M. T., Ajalloueian, F., \& Meyer, A. S. (2017a). Characterization of alginates from Ghanaian brown seaweeds: Sargassum spp. and Padina spp. Food Hydrocolloids, 71, 236-244.

Rhein-Knudsen, N., Ale, M. T., Ajalloueian, F., \& Meyer, A. S. (2017b). Characterization of alginates from Ghanaian brown seaweeds: Sargassum spp. and Padina spp. Food Hydrocolloids, 71(Supplement C), 236-244.

Rhim, J.-W. (2004). Physical and mechanical properties of water resistant sodium alginate films. LWT - Food Science and Technology, 37(3), 323-330.

Rinaudo, M. (2007). Seaweed Polysaccharides.

Schneider, C. W., \& Searles., R. B. (1991). Seaweeds of the southeastern United States: Cape Hatteras to Cape Canaveral.: Duke University Press.

Smidsrød, O., \& Skja k-Brtk, G. (1990). Alginate as immobilization matrix for cells. Trends in Biotechnology, 8, 71-78.

Stamatopoulos, K., Chatzilazarou, A., \& Katsoyannos, E. (2014). Optimization of Multistage Extraction of Olive Leaves for Recovery of Phenolic Compounds at Moderated Temperatures and Short Extraction Times. Foods, 3(1).

Széchy, M. T. M. d., Guedes, P. M., Baeta-Neves, M. H., \& Oliveira, E. N. (2012). Verification of Sargassum natans (Linnaeus) Gaillon (Heterokontophyta: Phaeophyceae) from the Sargasso Sea off the coast of Brazil, western Atlantic Ocean. Check List; Vol 8, No 4 (2012).

Toledo, R. T. (1991). Fundamentals of Food Process Engineering. (Third ed.). 
654 Torres, M. R., Sousa, A. P. A., Silva Filho, E. A. T., Melo, D. F., Feitosa, J. P. A., de Paula, R. C. 655 M., \& Lima, M. G. S. (2007). Extraction and physicochemical characterization of Sargassum vulgare alginate from Brazil. Carbohydrate Research, 342(14), 2067-2074. L. (2015). In Vitro Evaluation of Scaffolds for the Delivery of Mesenchymal Stem Cells to Wounds. BioMed Research International, 2015, 14.

660 Wedlock, D. J., \& Fasihuddin, B. A. (1990). Effect of formaldehyde pre-treatment on the intrinsic viscosity of alginate from various brown seaweeds. Food Hydrocolloids, 4(1), 41-47.

663

Whistler, R., \& BeMiller, J. N. (1959). Alkaline Degradation of Alginates.

664

665 concentrations of bioethanol from seaweeds: Production of high concentrations of bioethanol from seaweeds. Bioengineered, 4(4), 224-235.

666

667 
Table 1: Uronic acid sequence and $M / G$ ratio of sodium alginate samples

\begin{tabular}{lllllllll}
\hline & $\mathbf{F}_{\mathbf{G}}$ & $\mathbf{F}_{\mathbf{M}}$ & $\mathbf{F}_{\mathbf{G G}}$ & $\mathbf{F}_{\mathbf{M M}}$ & $\mathbf{F}_{\mathbf{G M}}$ & $\mathbf{F}_{\mathbf{M G}}$ & $\begin{array}{l}\mathbf{M} / / \mathbf{G} \\
\text { Ratio }\end{array}$ & Reference \\
\hline S. natans & 0.66 & 0.34 & 0.62 & 0.32 & 0.04 & 0.04 & 0.51 & This study \\
Sigma & 0.44 & 0.56 & 0.33 & 0.46 & 0.10 & 0.10 & 1.29 & This study \\
S. fluitans & 0.64 & 0.36 & 0.55 & 0.28 & 0.08 & 0.08 & 0.57 & (Davis et al., 2004) \\
S. oligocystum & 0.67 & 0.33 & 0.58 & 0.24 & 0.09 & 0.09 & 0.49 & (Davis et al., 2004) \\
S. dentifolium & 0.66 & 0.34 & 0.55 & 0.23 & 0.11 & 0.11 & 0.52 & (Larsen et al., 2003) \\
S. natans & 0.68 & 0.32 & 0.61 & 0.25 & 0.07 & 0.07 & 0.47 & (Rhein-Knudsen, Ale, \\
& & & & & & & & Ajalloueian, \& Meyer, 2017a) \\
S. thumbergii & 0.66 & 0.34 & 0.48 & 0.17 & 0.17 & 0.17 & 0.53 & (Davis, Llanes, Volesky, \& \\
& & & & & & & & Mucci, 2003)
\end{tabular}

Table 2: Sodium alginate yield and purity after multistage extraction and precipitation

\begin{tabular}{ccccc}
\hline & \multicolumn{2}{c}{ Multistage Extraction } & \multicolumn{2}{c}{ Multistage Precipitation } \\
Stage & Crude Yield (\%) & Cumulative Yield (\%) & True Yield (\%) & Purity (\%) \\
\hline 1 & 15 & 15 & 19 & 67 \\
2 & 2 & 17 & 15 & 71 \\
3 & $<1$ & 17 & 13 & 73 \\
4 & $<1$ & 17 & 10 & 74 \\
5 & $<1$ & 17 & 7 & 73 \\
\hline \multicolumn{2}{c}{ Sargassum Species } & True Yield (\%) & Reference \\
\hline \multicolumn{2}{c}{ S. subrepandum } & 21 & (Basha et al., 2011) \\
& S. turbinarioides & 10 & (Fenoradosoa et al., 2010) \\
& S. fluitans & 17.7 & (Davis et al., 2004) \\
& S. oligocystum & 18.6 & (Davis et al., 2004) \\
& S. latifolium & 4.3 & (Larsen et al., 2003) \\
& S. asperifolium & 12.1 & (Larsen et al., 2003) \\
& S. dentifolium & 3.3 & (Larsen et al., 2003) \\
\hline
\end{tabular}




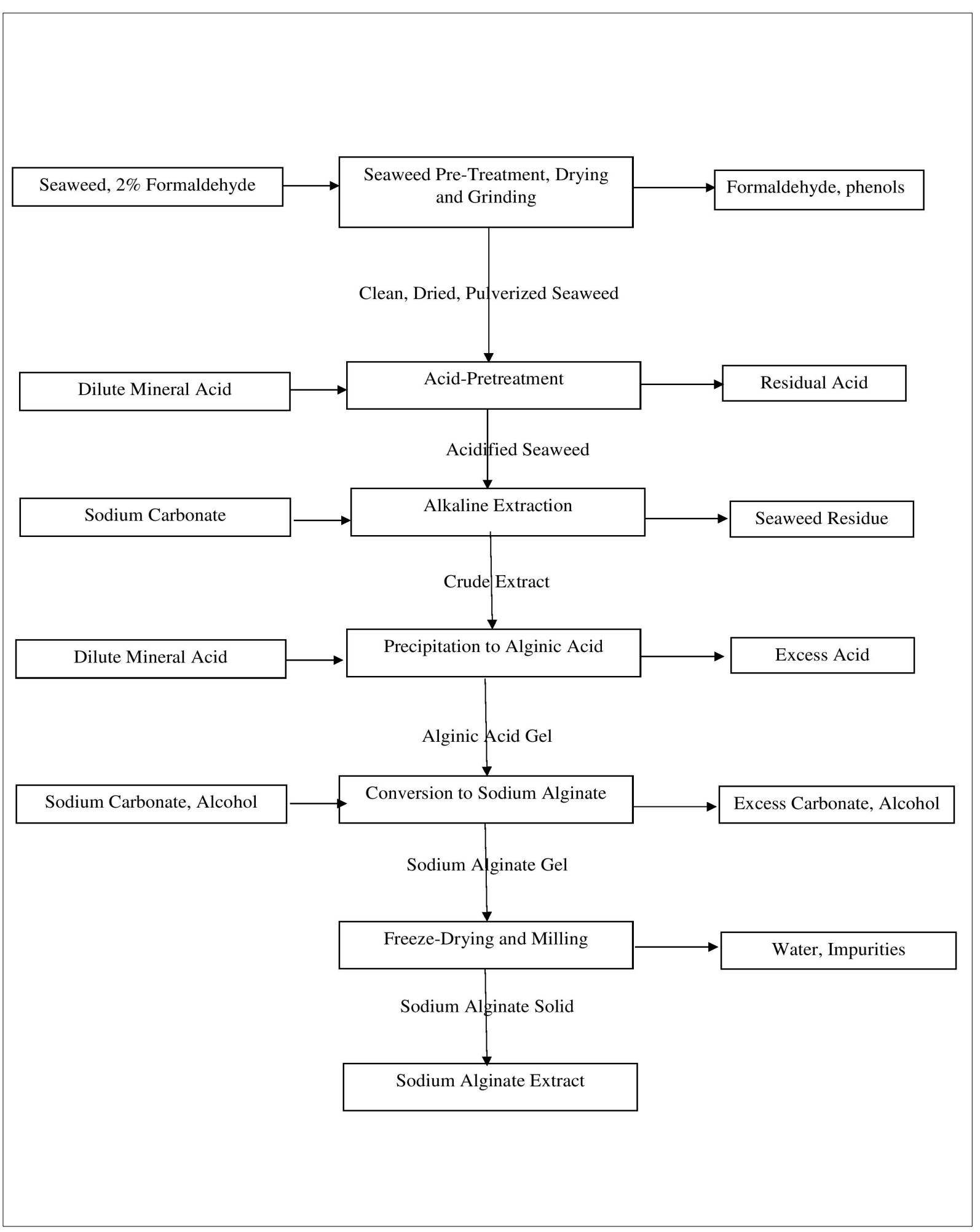

673 Figure 1: Overall process for extraction of sodium alginate from Sargassum natans. 


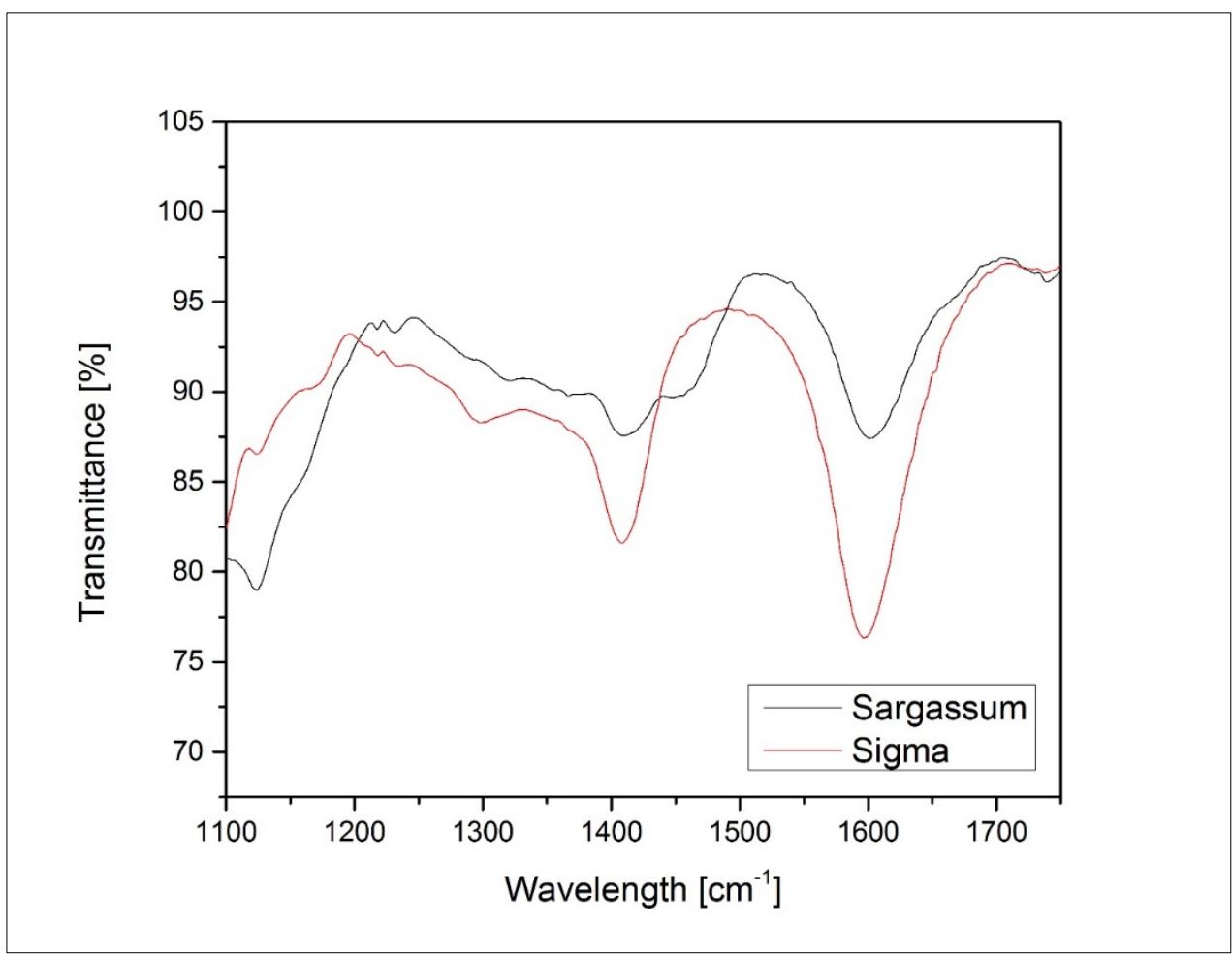

675 Figure 2: FTIR spectra of sodium alginate from extracted from Sargassum natans and that 676 of the commercial brand Sigma. 


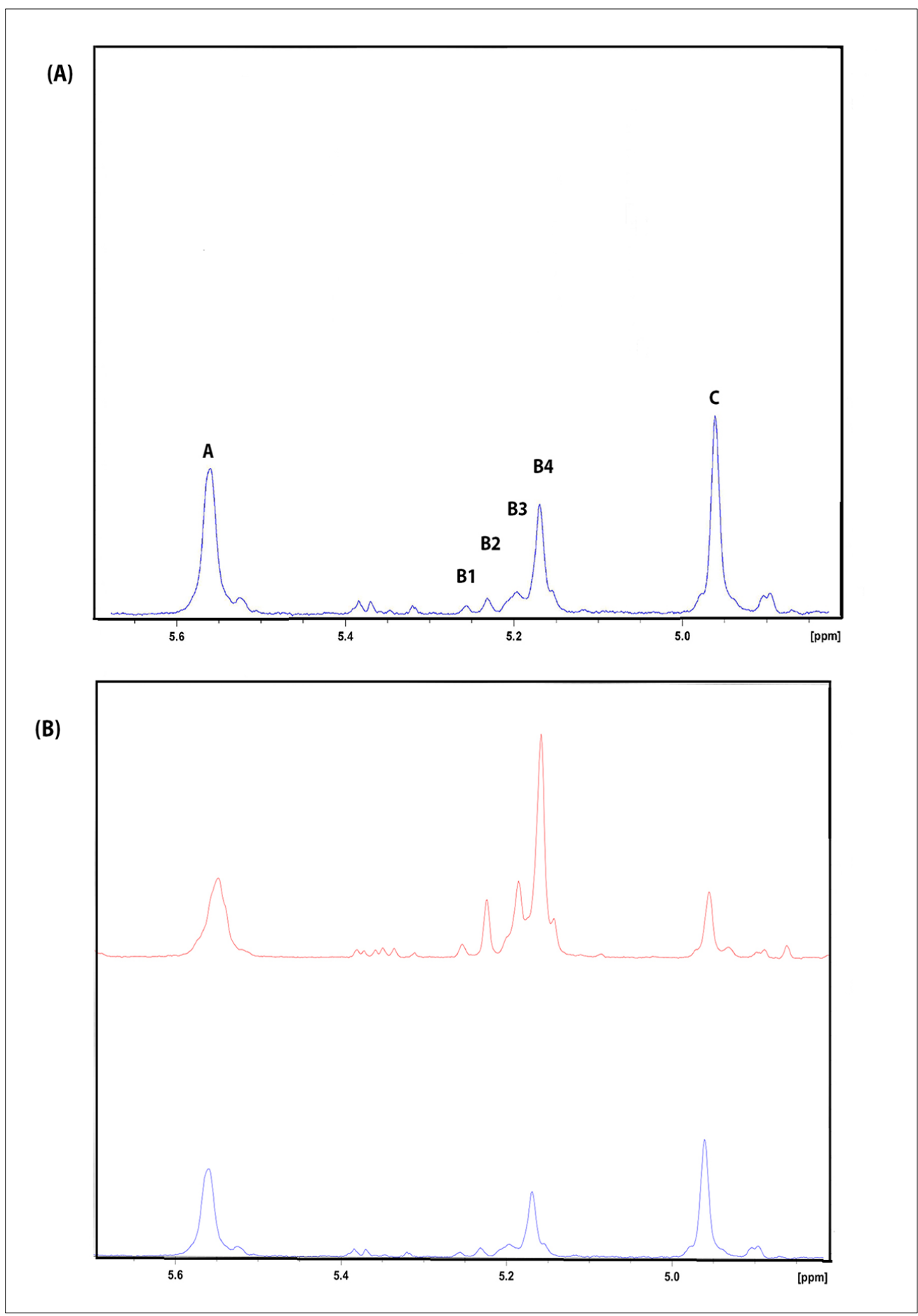

677

678 Figure 3: (A) NMR spectra of alginate extracted from Sargassum natans showing monads, 679 diads and triads. (B) Comparison of NMR spectra of alginate extracted from Sargassum 680

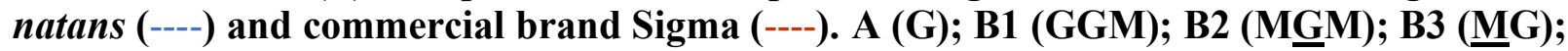

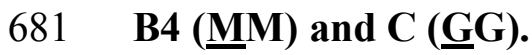


(A)

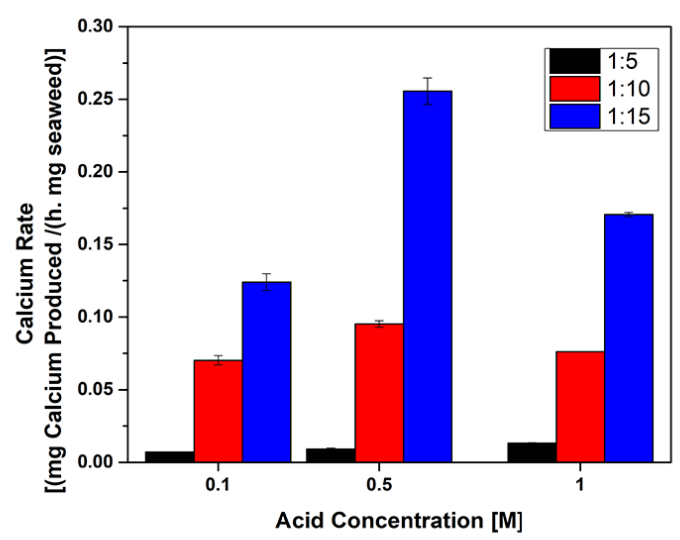

(B)

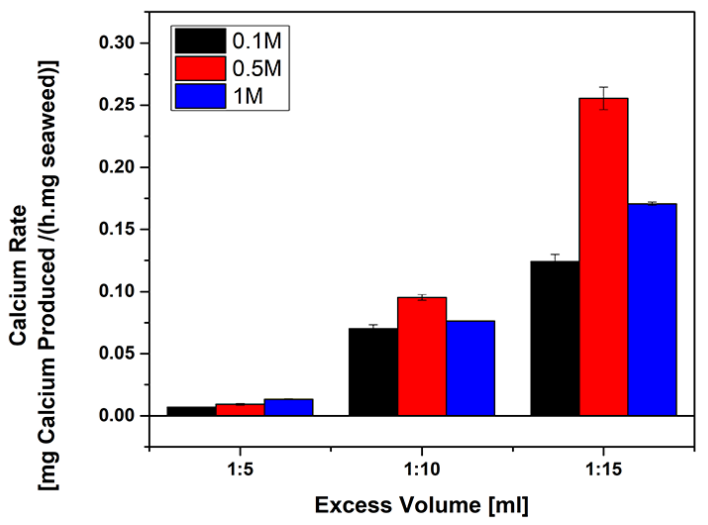

(C)

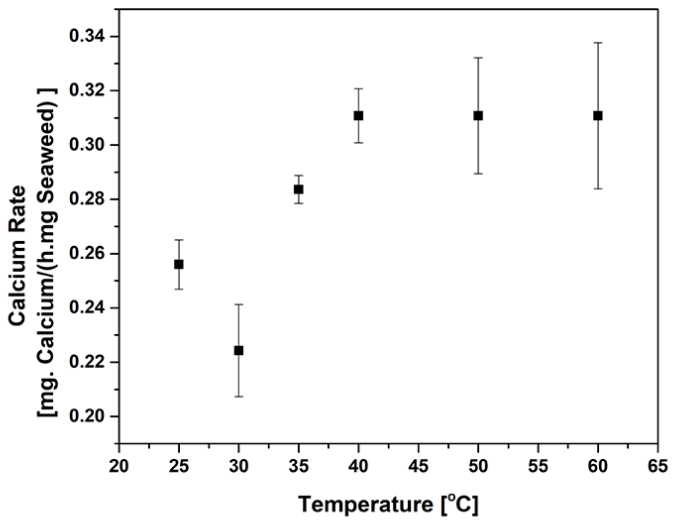

683 Figure 4: Calcium rate [mg. Calcium Produced/ (h.mg seaweed)] as a function of (A) Acid 684 concentration $[\mathrm{M}]$ at $25^{\circ} \mathrm{C}$. (B) Excess volumes $[\mathrm{mL}]$ at $25^{\circ} \mathrm{C}$. (C) Temperature $\left[{ }^{\circ} \mathrm{C}\right]$ using $685 \quad 0.5 \mathrm{M} \mathrm{H}_{2} \mathrm{SO}_{4}$ at $1: 15$ excess. 
(A)

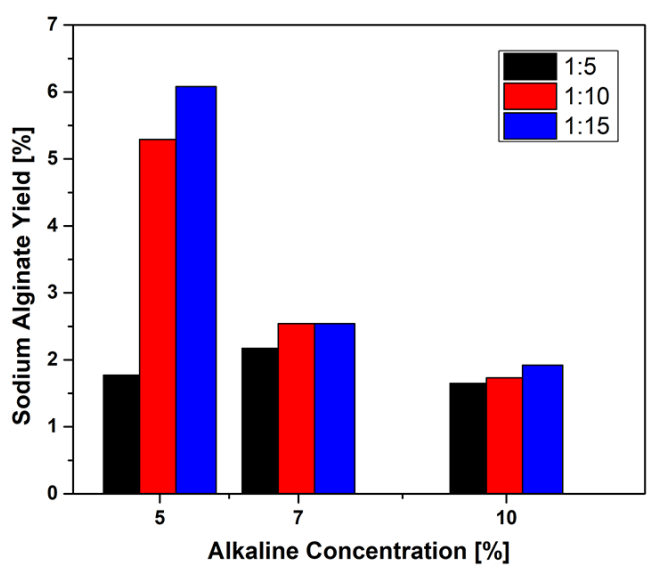

(C)

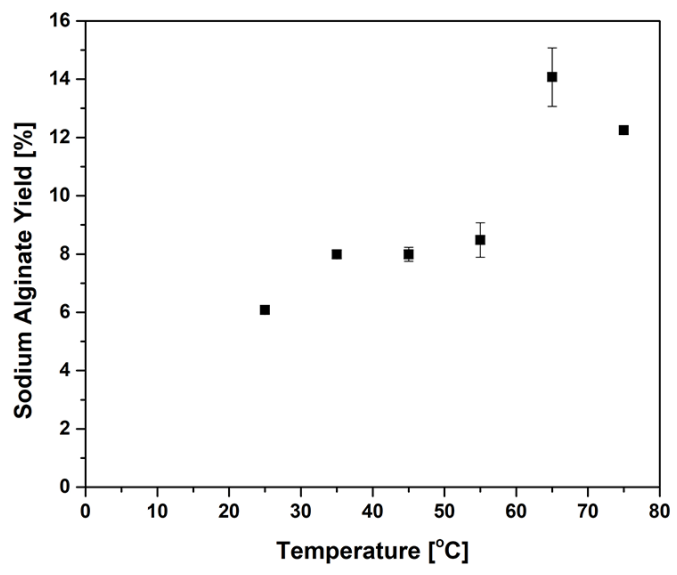

(B)

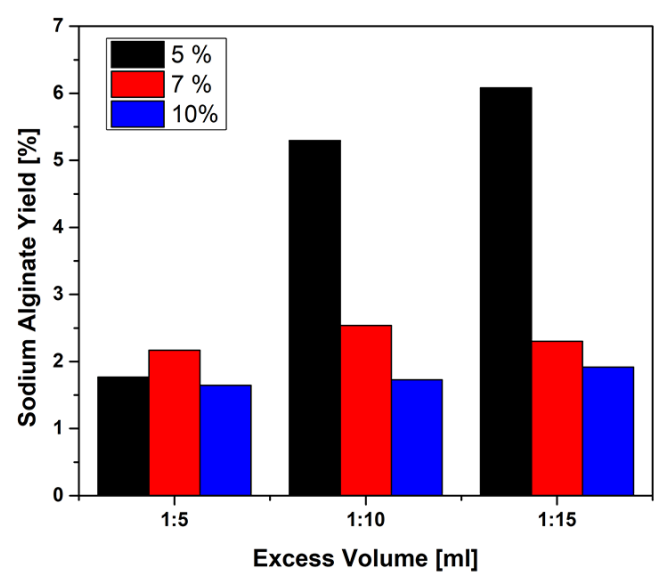

(D)

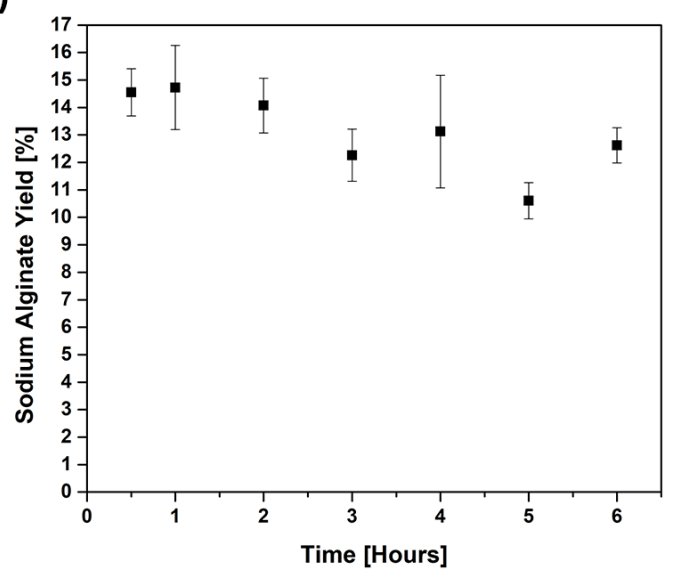

686

687

688

689

690

Figure 5: Yields of sodium alginate as a function of (A) $\mathrm{Na}_{2} \mathrm{CO}_{3}$ concentration [\%] for 2 hours at $25^{\circ} \mathrm{C}$. (B) At excess volume [mL] for 2 hours at $25^{\circ} \mathrm{C}$. (C) Temperature [ $\left.{ }^{\circ} \mathrm{C}\right]$ for 2 hours, using 5\% $\mathrm{Na}_{2} \mathrm{CO}_{3}$ and 1:15 excess volume. (D) Reaction time [Hours] using 5\% $\mathrm{Na}_{2} \mathrm{CO}_{3}$ and $1: 15$ excess volume at $65^{\circ} \mathrm{C}$. 
(A)

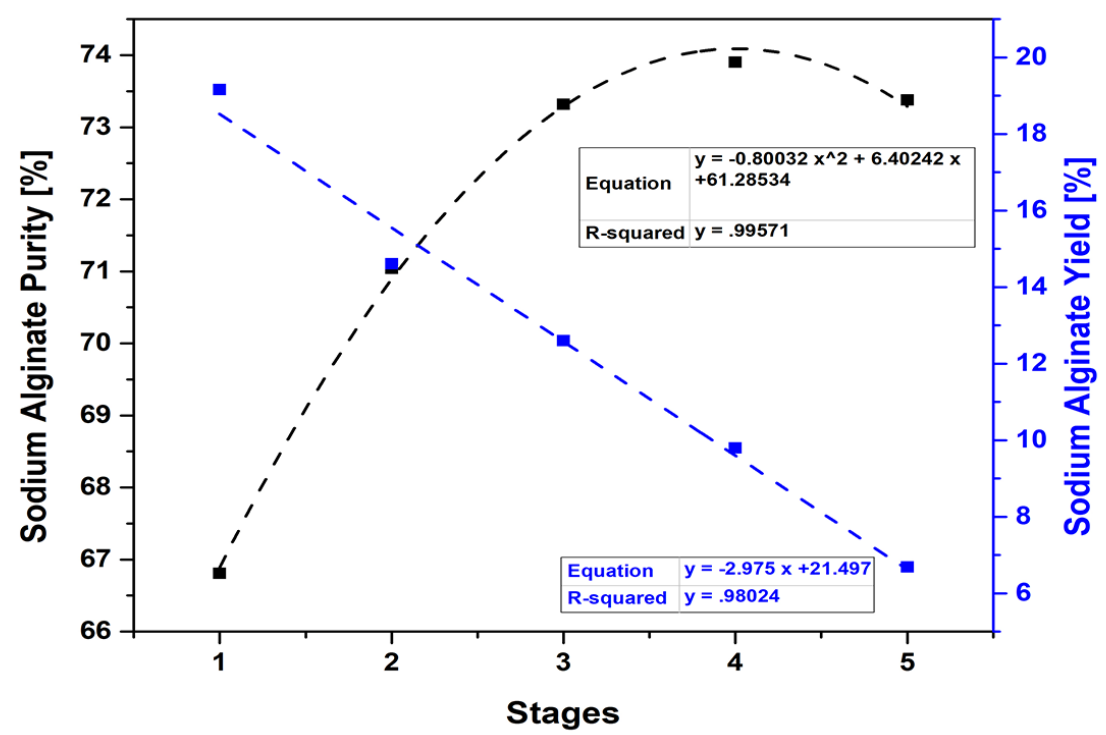

(B)

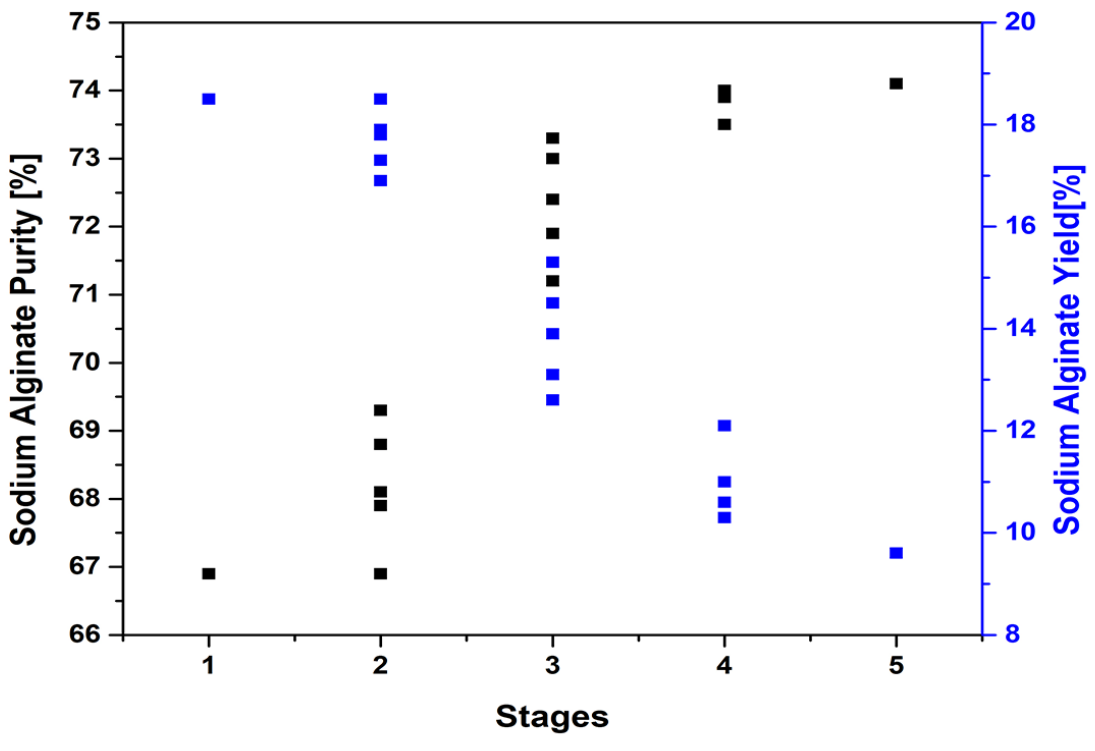

691

692 Figure 6: (A) Purity and yield of alginate extracted for increasing stages. (B) MATLAB 693 optimization model for purity and yield of alginate extracted for increasing stages. 